Agro-Science Journal of Tropical Agriculture, Food, Environment and Extension Volume 19 Number 4 (October 2020) pp. 6 - 13

ISSN 1119-7455

\title{
FACTORS AFFECTING HOUSEHOLDS' CHOICE OF COOKING ENERGY IN ENUGU STATE, NIGERIA
}

\author{
${ }^{1}$ Onyekuru N.A., ${ }^{* 2}$ Ifejirika C.A., ${ }^{3}$ Onuigbo D.M., ${ }^{4}$ Mebo R.A. and ${ }^{4}$ Eboh E.C. \\ ${ }^{1}$ Resource \& Environmental Policy Research Centre, \\ Department of Agricultural Economics, University of Nigeria, Nsukka 410001, Nigeria \\ ${ }^{2}$ Department of Agricultural Economics \& Extension, Federal University Oye-Ekiti, Nigeria \\ ${ }^{3}$ Department of Environmental Economics, University of Tasmania, Hobart, 7000 Australia \\ ${ }^{4}$ Department of Agricultural Economics, University of Nigeria, Nsukka 410001, Nigeria \\ *Corresponding author's email: chika.ifejirika@fuoye.edu.ng
}

\begin{abstract}
Households need energy for various activities, chief among these is cooking, which accounts for a greater percentage of the total domestic energy consumption. In Nigeria, household cooking energy accounts for a major part of the total energy consumed. This study was designed to explore the determinants of cooking energy use and preferences among households in Enugu State, Nigeria. Specifically, the aims of the study were; to ascertain the differences in the quantities of cooking energy sources used by households, determine the preferences of each of the energy sources by the households, reasons for preferences for each of the energy sources, and the problems associated with the use of each of the energy source. Multistage sampling technique was adopted in this study. One hundred and sixty-six respondents were used for the study. Primary data were collected and analyzed using a t-test and descriptive statistics. Results showed that the mean quantities of kerosene used in the rural and urban areas were about 26 and 36 litres per month that of fuel wood were about 231 and $306 \mathrm{~kg}$, respectively. The t-test result showed that there exist significant differences between the quantities of kerosene and fuel wood used in the rural and urban areas. The likert-type scale result showed that the cooking energy with the highest perceived level of efficiency was liquefied petroleum gas (LPG), while the energy with the highest level of preference was kerosene. The major reasons for the preference for LPG was because it cooks fast and clean, that of kerosene was lower chances of fire accident than LPG. For fuel wood, preference was due to fast cooking and better taste of food, while that of charcoal was due to clean cooking and reduced cases of fire accident. The major constraints militating against the use of different cooking energy sources, even when they are preferred, were scarcity, expensiveness and risk of fire outbreak for LPG and kerosene, while for fuel wood and charcoal, they were pollution and the fact that it produces a lot of black soot. There is need to implement incentive-based policies to encourage the use of LPG and kerosene, through targeted subsidies and cost reduction.
\end{abstract}

Key words: energy consumption, efficiency, preference, pollution, income

\section{INTRODUCTION}

Energy is a major component of the social, economic and industrial development of any nation (Oyedepo, 2012; Chukwu et al., 2014). Almost, half of the world's population depends on solid fuels for household cooking (Bonjour et al., 2013). In Africa, access to modern, affordable and reliable energy services is a huge challenge, especially in Nigeria (Baiyegunhi and Hassan, 2014). In Nigeria, household cooking energy accounts for a major part of the total energy consumed (Emagbetere et al., 2016). The total energy consumption taken by the households in Nigeria is about $65 \%$; this can likely be attributed to the under development of the industrial sector (Oyedepo, 2012). Household cooking consumes more energy than any other enduse services in low income developing countries
(Daioglou et al., 2012). Households need energy for various activities, chief among these is cooking which accounts for a greater percentage of the total domestic energy consumption. (Oyedepo, 2012). Unfortunately, this area (household cooking energy consumption) has not received adequate attention from the international and local communities. Despite the abundance of renewable, environmentally friendly energy sources, about three billion people worldwide still use solid fuels for their basic needs which include cooking (Hossain, 2012). In less industrialized countries, energy for cooking constitutes 70 to $90 \%$ of total energy (Energy Sector Management Assistance Program (ESMAP), 2007). Approximately, about 2.5 billion people in these countries rely on biomass fuels (such as firewood, charcoal, and 
animal dung) to meet their cooking energy needs (World Health Organization (WHO) and United Nations Development Programme (UNDP), 2009).

Firewood followed by charcoal are the most widely used solid cooking fuels but their burning is accompanied with pollution which constitute health hazard (Bisu et al., 2016). In addition, the use of solid fuel also has some environmental implications like increase greenhouse gas emission, deforestation and desert encroachment. Firewood is the oldest cooking fuel. It is relatively abundant in the rural areas than in the urban areas. It is synonymous with fuelwood. Other cooking fuels are electricity, sunlight (solar energy), processed plant wastes and biogas. Households in developing countries generally use solid fuels, biogas and LPG for cooking. Kerosene is mainly used for cooking and lighting while natural gas is used for cooking and heating.

Some studies have attempted to assess the household energy choice and preference in Nigeria. Bisu et al. (2016) examined urban household cooking energy choice in Bauchi metropolis of Nigeria. Emagbetere et al. (2016) assessed household energy utilized for cooking in Ikeja, Lagos state, Nigeria. Olufemi et al. (2012) studied the pattern and determinants of household sources of energy for cooking in rural and urban south western, Nigeria. These studies however focused on the northern and Western part of the countries with little or no attention on factors that determine households' choice of these cooking energy. The multifaceted impacts of household cooking energy sources on health, environment, and cost, adequate data relevant to the subject matter is not available. Presently, there is little data documented in Nigeria on the current level of utilization of cooking energy sources among households. Therefore, producing more data related to household cooking energy sources and their preferences by households is believed to fill the existing knowledge gap. Thus, there is paucity of information on household energy statistics at state level in Nigeria. This study examined the energy use, preference and also determined current level of utilization of cooking energy sources by households in Enugu State, Nigeria.

Household cooking energy can be categorized based on the level of energy development into traditional (firewood, agricultural wastes, etc.), intermediate (charcoal, coal, kerosene, etc.) and modern (solar, liquefied petrol gas (LPG), electricity, etc.). Based on the method of production; they can be classified into primary (from natural resources, e.g., firewood) and secondary (from transformation of primary energy sources). Cooking energy can also be classified into renewable (biomass, solar, biogas) and nonrenewable (coal, kerosene, LPG) (Malla and Timilsina, 2014). We can also classify them as solid (firewood, charcoal, coal, etc.) and non-solid (LPG, kerosene, electricity, etc.) fuels.
Household choice of energy can be explained with the 'Energy Ladder Model'. This model categorizes household energy into three classes namely: traditional, transition and advanced energy sources. Low income households use traditional energy sources. When their income improves, they move to transitional energy sources. Further increase in their income will propel them to move to advanced energy sources. Thus, the energy ladder model is based only on income of households neglecting the other factors and receives a lot of criticisms in this regard. As a result of the weaknesses of the energy ladder model, other models like the fuel stacking model have been recommended. This model presumes that household energy consumption patterns depend on several factors (e.g., social, economic, cultural and personal choices) apart from income. Thus, rather than transcending to cleaner fuels, households tend to increase the number of fuels used without abandoning the old ones (Risseeuw, 2012). This has been buttressed by researchers such as Ogwumike et al. (2014), Malla and Timilsina (2014) and Yonemitsu et al. (2015), who discovered that fuel stacking is practiced more by households with higher income. In other words, households increased the number of fuels they used as their income increased. This was supported by Nnaji et al. (2012) who found that firewood is the energy choice for larger families.

Literature has shown that several socioeconomic factors affect household's choice of energy. Such factors include income, education, and household size, ownership of the house, age and type of home. For instance, firewood consumption rate decreases with increase in household income. Thus, the broad objective of this study is to explore the factors that determine the choice of household cooking energy use in Enugu State. Specifically, this paper ascertained the differences in cooking energy use by households determine the perceived levels of efficiency and preferences of energy sources by the households and ascertain the constraints associated with the use of each of the energy source.

\section{MATERIALS AND METHODS}

\section{The Study Area}

The study area is Enugu State, Nigeria. The State occupies a land area of 71,161 square kilometres with a population of $4,411,119$ people, of which $85 \%$ of them live in the rural areas of the state (National Bureau of Statistics (NBS), 2018). Enugu State is located between latitudes $5^{\circ} 56^{1} \mathrm{~N}$ and $7^{\circ} 6^{1} \mathrm{~N}$ and longitudes $653^{\circ} \mathrm{E}$ and $7^{\circ} 55^{1} \mathrm{E}$ of Greenwich Meridian (Enugu State Agricultural Development Programme (ENADEP) 2004; Federal Government of Nigeria (FGN), 2001). 
It shares boundaries with Anambra State on the West, Abia State on the South, Kogi State on the North and Benue and Ebonyi States on the East. The State has 17 Local Government Areas and according to ENADEP (2004), the State is further divided into three agricultural zones based on the similarities in soil characteristics and by extension meteorological properties (Figure 1). The zones include Enugu zone, Awgu zone and Nsukka zone.

\section{Sampling Procedures}

Multistage sampling method was adopted in this study. In the first stage three urban and rural areas were purposively selected from each of the three agricultural zones. This was to ensure that true urban and rural areas were selected and not semi or peri rural or urban areas. In the second stage, the rural and urban areas selected were divided into clusters according to the INEC political wards with a list of political wards from the Enugu State Ministry of Local Government Co-ordinating Department.

From each of the three urban areas in Enugu State namely; Enugu, Oji-River and Nsukka, two wards were purposively selected in order to use areas with dense population of households and not business or office areas. The wards are Abakpa 1 and Onu Asata from Enugu, Oji River 1 and Oji River II from Oji River and University of Nigeria Community and Mkpunano from Nsukka. From the rural areas, two wards were randomly selected, from each of the three agricultural zones in Enugu State. They are Ngwo Uno and Okpatu from Enugu, Inyi I and Achiuno IV from Oji River, Edem Ani and Alor Uno from Nsukka, giving a total of twelve wards in all. The last stage was the random selection of seventeen households from each of the selected wards, this was for convenience and not necessarily to get proportionate sample, giving a total of 204 respondents. The sample frame was made up of all the households in each of the wards.

\section{Data Collection and Analysis}

Data required for the study were collected from primary sources. With the help of trained enumerators, primary data were collected through administered questionnaires. The information collected using primary source were socioeconomic characteristics of the households, pattern and levels of energy use, the constraints to energy use, level of efficiency of each of the energy sources and levels of preference of the households to the different energy sources. A total of two hundred and four questionnaires were distributed and one hundred and sixty-six were successfully collected. Data were analyzed using descriptive statistics including percentages, charts, Likert-type scale and t-test.

\section{Model Specification}

Descriptive statistics such as frequency, percentage and charts were used to describe the socio-economic characteristics of the respondents and level of usage. T-test was used to test for a significant difference between the quantities of kerosene used in the rural and urban areas and the quantities of fuel wood used in the rural and urban areas, thus:

$$
t-c a l=\frac{\bar{X}_{1}-\bar{X}_{2}}{\sqrt{\frac{s_{1}^{2}}{n_{1}}+\frac{s_{2}^{2}}{n_{2}}}}
$$

where $\bar{X}_{1}$ is mean of kerosene/fuelwood quantities in the rural areas, $\bar{X}_{2}$ is mean of kerosene/ fuelwood quantities in the urban areas, $n_{1}$ and $n_{2}$ represent sample size in the rural and urban areas respectively, and $s_{1}$ and $s_{2}$ represent standard deviation for $n_{1}$ and $n_{2}$, respectively.

$$
\text { Hypothesis: } \begin{array}{r}
\mathrm{H}_{0}: \bar{X}_{1}=\bar{X}_{2} \\
\mathrm{H}_{1}: \bar{X}_{1} \neq \bar{X}_{2}
\end{array}
$$

A three-point Likert-type scale was used to analyse the problems associated with the use of each of the cooking energy sources $(3=$ very serious, $2=$ serious, and $1=$ not serious). In the analysis, the sample mean of the identified problems was calculated to be 2.0. Thus, any option with a mean equal to or greater than 2.0 was said to be a serious problem, while any option that has a mean less than 2.0 was recorded as not serious. Also, a four-point Likert-type scale was used to analyse the perceptions of the households on the levels of efficiency of each energy source. The options used in the scale were; very efficient (4), efficient (3), moderately efficient (2) and not efficient (1). The mean score was calculated by the summation of the values of the scaling options; $4+3+2+1=10$, then dividing by 4 gives 2.5 . Thus, any energy source that has a mean score equal to or greater than 2.5 is said to be efficient, while those less than 2.5 are said to be inefficient in cooking. In the case of this study, efficiency is contextualized as a function of the combination of relative speed of cooking, handling and cleanness of the cooking energy source, as was conceptualized by the respondents.

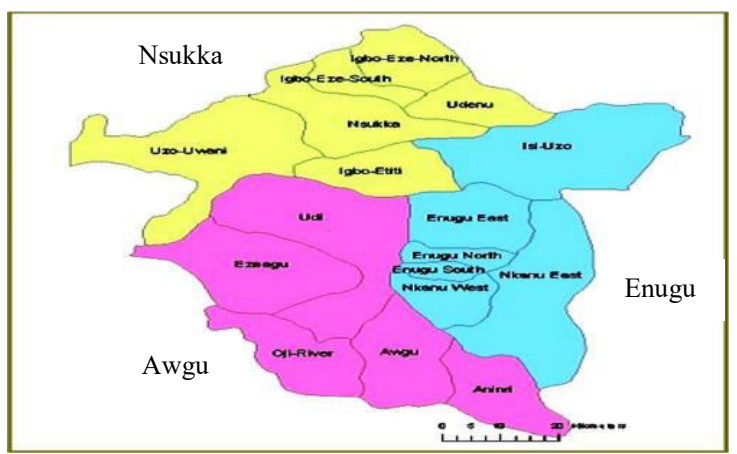

Figure 1: Map of Enugu State showing the three agricultural zones 


\section{RESULTS AND DISCUSSION}

Socio-Economic Characteristics of the Respondents

Description of some of the relevant socio-economic characteristics of the respondents are presented (Table 1). About $76.5 \%$ of respondents in the rural areas were involved in other occupations other than farming. It might look surprising that only $23.5 \%$ of the respondents in the rural areas were farmers. The reasons are not far-fetched. To start with, most people in the rural areas have different occupations apart from their farming activities; they devote more of their time to artisan work and only go to farm when they do not have much to do or at the peak of farming season and return to continue with their other occupations. So, they prefer to be recognized by their other occupations than be called farmers. Secondly, some of those who were farmers could not fill the questionnaires as they were always in the farm and rarely spare time to sit for questioning. Thus, out of the 102 questionnaires administered in the rural areas only 68 were successfully completed. While in the urban areas other occupation apart from farming (artisan, traders, civil servants, etc.) accounted for about $97.1 \%$. This result is in line with expectation as most people in urban areas across the world engage in occupations other than farming.

From the results, majority of the respondents in the rural areas went to secondary schools as it has the highest percentage of 36.8 , followed by those that attended primary school, $29.4 \%$ while in the urban areas most of the respondents fell into the educational category of tertiary education with the highest percentage of $38.8 \%$ followed by those that went to secondary schools with a percentage of $30.6 \%$. This result shows that at least most of the respondents were literate enough to understand the essence of the research and communicate with the field workers effectively. According to Karakara et al. (2019) educational attainment of a person especially the household head, could have an effect on the type of energy source used by the household.

In terms of household size, majority of the respondents in the rural areas had household size range of 5 to 6 with a percentage of 31 , followed by range 3 to 4 having a percentage of 23.5. In the urban areas, about $30.6 \%$ of the respondents had family sizes between 7 and 8 which have the highest percentage, followed by family size 3-4 with a percentage of 23.5. On the average the family size of the respondents was 5 , showing that the households have moderately large family sizes, thus will have a great impact on their cooking energy need. This is in line with the view of Karakara et al. (2019) who asserted that the size of a household is considered to have an effect on the type of energy source used.

The result also shows that majority of the respondents in the rural areas fell within the income category of $\$ 11,000$ and $\$ 30,000.00$ per month which had the highest percentage of 57.4; while in the urban areas the income range of most of the respondents was $\$ 31-50,000$ with $34.4 \%$, followed by income ranges of $11,000-30,000$ and, $\$ 1,000-100,000$ with $26.5 \%$ and $25.5 \%$, respectively. These results show that the households were far below average in terms of income security and therefore may find it difficult meeting up with their energy needs in the face of rising energy bill. Thus, the income level of a household can serve as a basis to determine the energy source they will choose to adopt (Olufemi et al., 2012; Faisal et al., 2013; Tchereni, 2013).

Test of Difference between Quantities of Kerosene and Fuelwood used in the Rural and Urban Areas of Enugu State

The result of the test of significant difference between the quantities of kerosene and fuelwood used in the rural and urban areas is as shown in Table 2. Charcoal and LPG were not included in this analysis because their use among the rural households were very negligible to be compared with the urban households.

Result of the analysis shows that the mean quantities of kerosene and fuelwood used by the rural households were less than those of their urban counterparts. The value for t-calculated was -2.027 with a $p$ value of 0.047 for kerosene users while, for fuelwood users, the value for the t-calculated was -2.158 , with a $p$ value of 0.035 , both significant at $5 \%$ level of probability. This indicates that there are significant differences between the quantities of kerosene and fuelwood used in the rural and urban areas of the state. The result shows that the mean

Table 1: Socio economic characteristics of the households in the rural and urban areas

\begin{tabular}{|c|c|c|c|c|}
\hline \multirow[t]{2}{*}{ Variables } & \multicolumn{2}{|c|}{ Frequency } & \multicolumn{2}{|c|}{ Percentage } \\
\hline & Rural & Urban & Rural & Urban \\
\hline \multicolumn{5}{|l|}{ Occupation } \\
\hline Farming & 16 & 2 & 23.5 & 2.9 \\
\hline Others & 52 & 96 & 76.5 & 97.1 \\
\hline Total & 68 & 98 & 100.0 & 100.0 \\
\hline \multicolumn{5}{|l|}{ Educational level } \\
\hline None & 6 & 1 & 8.8 & 1.1 \\
\hline $1-16$ & 20 & 17 & 29.4 & 17.3 \\
\hline $7-12$ & 25 & 30 & 36.8 & 30.6 \\
\hline $13-16$ & 17 & 38 & 25 & 38.8 \\
\hline Above 16 & 0 & 12 & 0 & 12.2 \\
\hline Total & 68 & 98 & 100.0 & 100.0 \\
\hline \multicolumn{5}{|l|}{ Household size } \\
\hline $1-2$ & 12 & 10 & 17.6 & 10.2 \\
\hline $3-4$ & 16 & 23 & 23.5 & 23.5 \\
\hline $5-6$ & 21 & 21 & 31.0 & 21.4 \\
\hline $7-8$ & 11 & 30 & 16.2 & 30.6 \\
\hline $9-10$ & 6 & 10 & 8.8 & 10.2 \\
\hline $11-12$ & 2 & 4 & 2.9 & 4.1 \\
\hline Total & 68 & 98 & 100.0 & 100.0 \\
\hline \multicolumn{5}{|l|}{ Household income } \\
\hline 10,000 and below & 7 & 2 & 10.3 & 2.1 \\
\hline $11,000-30,000$ & 39 & 26 & 57.4 & 26.5 \\
\hline $31000-50,000$ & 17 & 34 & 25.0 & 34.6 \\
\hline $51000-100,000$ & 4 & 25 & 5.9 & 25.5 \\
\hline $101000-200,000$ & 0 & 3 & 0 & 3.1 \\
\hline 200,000 and above & 1 & 8 & 1.4 & 8.2 \\
\hline Total & 68 & 98 & 100.0 & 100.0 \\
\hline
\end{tabular}


quantity of fuelwood used by urban households $(306.20 \mathrm{~kg})$ is higher than that of rural households $(230.89 \mathrm{~kg})$. This is contrary to apriori expectation, as those of the rural households were expected to be higher. This is as a result of the fact that most rural households only reported quantities of fuelwood they bought rather than the total quantities used since it was difficult for them to estimate the quantities they collected from the forest themselves.

\section{Constraints to the Use of the Energy Sources}

The constraints associated with the use of each of the cooking energy sources were presented in Table 3 . From the results, the following deductions can be made about the constraints militating against the use of each of the cooking energy sources.

\section{i) Liquefied Petroleum Gas (LPG)}

The constraints militating against the use of cooking gas were identified as: low technical know-how, scarcity, risk of fire accident and high cost with the means of $2.6,2.5,2.5$ and 2.5 , respectively. The result found that low technical know-how in the operation of gas cooker had the highest mean of 2.6. This may be because many people in the study area lack the knowledge of its operation and are afraid of the usage to avoid fire accident. This fear was further aggravated by the rampant cases of fire accidents due to LPG misuse. The other constraints as identified in Table 3 were largely due to the expensive nature of the product, its scarcity, poor education and low income. In this regard, the households consider LPG as not being readily available or/and expensive, especially in the rural areas. This finding is in resonance with that of Olufemi et al. (2012) that households demand for energy is significantly related to household income.

\section{ii) Kerosene}

The result also noted problems faced by households in the use of kerosene source as: scarcity (2.8), high cost (2.8) low income (2.6), large household size (2.5), poor education (2.3), risk of fire accident
(2.0) and low technical know-how (2.0). The result revealed that scarcity and high cost of kerosene had the highest mean of 2.8 each, indicating that they are very serious. This problem is usually experienced more in the rural areas where there were no filling stations for the people to access kerosene. Rather they depend on retailers and black marketers for their supply. The lower mean of 2.0 for risk of fire accident and low technical know-how is due to the fact that most people know how to use kerosene. Apart from the few cases of fire accidents reported from the use of adulterated kerosene, kerosene would have been safe to use; it is rare to experience kerosene fire accident as is the case with LPG, which has a mean of 2.5 for risk of fire accident. To buttress this, Lam et al. (2012) opined that relative to LPG, kerosene has a low vapour pressure which reduces its risk of explosion (fire outbreak).

\section{iii) Fuelwood}

For fuelwood, it was seen that the problems faced by the households were pollution and the fact that it produces a lot of black soot (dirty) that causes stains with means of 2.5 each. This was obvious as these two problems were the major hindrances to the use of fuelwood. This finding is also in line with those of Otte (2014) and Mwampamba et al. (2013), who posit that the use of firewood is associated with negative health and environmental consequences associated with air pollution.

\section{iv) Charcoal}

In the case of the use of charcoal, the constraints found in the study area were pollution and production of black soot with means of 2.0 and 2.2, respectively. This finding is also in agreement with that of Emagbetere, et al. (2016), who found that charcoal users were not satisfied because of its uncleanness. Regardless of this, charcoal has relatively lower pollution level and production of black soot than fuelwood, thus resulting to its preference in the urban centres for indoor cooking.

Table 2: Test of difference between quantities of kerosene and fuelwood used in the rural and urban areas of Enugu State

\begin{tabular}{|c|c|c|c|c|c|c|c|}
\hline \multirow{2}{*}{\multicolumn{2}{|c|}{ Variable }} & \multirow[t]{2}{*}{$\mathrm{N}$} & \multirow[t]{2}{*}{ Mean } & \multirow[t]{2}{*}{$\mathrm{T}$} & \multirow{2}{*}{$\begin{array}{l}\text { Sig } \\
(2 \text {-tailed })\end{array}$} & \multicolumn{2}{|c|}{$95 \%$ confidence interval of the difference } \\
\hline & & & & & & Lower & Upper \\
\hline \multirow{2}{*}{ Kerosene } & Rural & 33 & $26.09^{ \pm} 2.81$ & $-2.027^{*}$ & 0.047 & -19.4318 & -0.13637 \\
\hline & Urban & 32 & $35.88^{ \pm} 3.96$ & & & & \\
\hline \multirow[t]{2}{*}{ Fuelwood } & Rural & 35 & $230.89^{ \pm} 18.81$ & $-2.158^{*}$ & 0.035 & 34.91 & 145.07 \\
\hline & Urban & 30 & $306.20^{ \pm} 30.68$ & & & & \\
\hline
\end{tabular}

Note asterisks $(*)$ indicate statistical significant at $5 \%$ probability level

Table 3: Constraints to the use of cooking energy source

\begin{tabular}{|c|c|c|c|c|c|c|c|c|}
\hline \multirow[t]{2}{*}{ Constraints } & \multicolumn{2}{|c|}{ LPG } & \multicolumn{2}{|c|}{ Kerosene } & \multicolumn{2}{|c|}{ Fuelwood } & \multicolumn{2}{|c|}{ Charcoal } \\
\hline & $x$ & SD & $x$ & SD & $x$ & SD & $\bar{x}$ & SD \\
\hline Poor education & 2.4 & 0.9 & 2.3 & 0.9 & 1.5 & 0.5 & 1.3 & 0.5 \\
\hline Low income & 2.3 & 0.6 & 2.6 & 0.7 & 1.5 & 0.5 & 1.3 & 0.5 \\
\hline Scarcity & 2.5 & 0.5 & 2.8 & 0.5 & 1.7 & 0.5 & 1.5 & 0.5 \\
\hline Risk of fire accident & 2.5 & 0.8 & 2.0 & 0.6 & 1.3 & 0.5 & 1.2 & 0.4 \\
\hline Low technical know-how & 2.6 & 0.8 & 2.0 & 0.7 & 1.3 & 0.6 & 1.3 & 0.6 \\
\hline High cost & 2.5 & 0.5 & 2.8 & 0.5 & 1.5 & 0.5 & 1.5 & 0.5 \\
\hline Pollution & 1.3 & 0.5 & 1.3 & 0.7 & 2.5 & 0.8 & 2.0 & 1.0 \\
\hline Increase in household size & 1.8 & 0.8 & 2.5 & 0.8 & 1.3 & 0.7 & 1.3 & 0.4 \\
\hline Dirty to use & 1.2 & 0.4 & 1.9 & 0.9 & 2.5 & 0.9 & 2.2 & 0.8 \\
\hline
\end{tabular}

$x$ - mean, SD - standard deviation 


\section{Households Perceived Levels of Efficiency of the Different Energy Sources}

This section analyses the perceptions of the households on levels of efficiency and preferences for each of the energy sources. From Figure 2, it is seen that the cooking energy with the highest perceived level of efficiency was identified to be cooking gas (LPG), with a mean of 3.6, followed by kerosene with a mean of 3.1, next was fuelwood, with mean of 2.5 and charcoal, with a mean of 1.9 . This finding agrees with that of Emagbetere et al. (2016), where majority of the respondents preferred LPG followed by kerosene. Charcoal was seen to be the least in order of preference as only $2.0 \%$ of the sample preferred it. This finding implies that charcoal is not efficient in comparison to others; though charcoal cooks more neatly than firewood and kerosene, it wastes a lot of time to kindle. In most cases a lot of charcoal burn up as waste.

The findings show that although the households agree that LPG and kerosene are more efficient in cooking, they prefer to use less efficient energy source. There is therefore no other behavioural driver in this regard apart from the cost of the energy sources, which favours the use of fuelwood and charcoal as cheaper and readily available alternatives, especially in the rural areas. It is for this reason that it poses very devastating danger to forests and the environment due to excessive cutting down and burning of wood. There is therefore a need to implement incentivebased policies to encourage the use of LPG and kerosene, through targeted subsidies and cost reduction for the duo in order to help save our forest.

\section{Level of Preference of Energy Sources}

The preferences of the households for the different energy sources were realized using percentage and presented in Figure 3. The result followed the same trend as households' perception of levels of efficiency, except that the energy with the highest level of preference was kerosene as against LPG that had the highest level of perceived efficiency. Figure 3 shows that about $43 \%$ of the households preferred kerosene to others. This may be because many households look at it as "energy of convenience" as it is easy and amenable to different kinds of cooking, anytime, anywhere with less exposure to risks. This result confirms earlier results about the level of importance of kerosene to the livelihoods. Anything that affects its supply goes a long way to affect the total household welfare, both in terms of their budget and availability of kerosene for cooking.

Reasons for Preference of Cooking Energy Sources To understand the factors driving households' preferences, they were further asked to indicate why they prefer one energy source to another, the result is shown in Table 4. The result shows the two major reasons why households preferred cooking gas were speed of cooking and neatness with percentages of 31.9 and 30.0 respectively. In the case of kerosene, reduced cases of accident had the highest percentage of 23, followed by clean cooking and easiness to use, that had percentages of 19.4 and 18.1 , respectively. The reasons why some people prefer charcoal were that; it has low cases of fire accident, clean cooking and easy to use with percentages of 21.4 each.

The households' preference for fuelwood even when other energy sources are available and affordable was due to the special taste they get from food cooked with firewood. This is in line with Kumlachew et al. (2014), that people still believe that food cooked with traditional energy source tastes delicious than those cooked with other cooking energy sources. This perception is more prevalent in the rural areas and especially with older people, who never eat food that is not cooked with firewood. They can identify dishes that are not cooked with firewood by the taste.

Next in order of importance was the issue of family size, with a percentage of 17.8 , the larger the family size and the quantity of food to be cooked, especially in ceremonies, the more economical it was to use fuelwood. This finding is in tandem with that of Bisu et al. (2016), who found that peoples' choice of energy source for cooking is influenced by its availability, education, income, household size and location. Also, Massawe et al. (2015) found that in Tanzania, fuelwood is the major source of cooking energy, especially in the rural areas. This can be as a result of its availability, either through free collection from the forest, buying or both. The other important reasons were fastness in cooking and lack of kerosene with $15.9 \%$ each.

\section{Why Households Do Not Use Their Preferred Cooking Energies}

Preference does not mean usage. From the research, it was discovered that most people do not use their preferred cooking energy sources owing to one reason or the other (Table 5). This finding is also in line with Emagbetere et al. (2016) that respondents utilize energy sources that are contrary to their preference. In this section therefore, a vivid description of the reasons why households do not use their preferred energy sources were examined (Table 5).

Though it was seen from previous sections that $33.7 \%$ of the sample preferred to use cooking LPG, only $2.4 \%$ of the entire sample used the energy source. This was about $7.1 \%$ of those that preferred cooking gas. The reasons for this are obvious as $52 \%$ do not use gas because it is expensive, $30.7 \%$ for fear of fire accident its high level of efficiency and neatness notwithstanding, while the rest $17.3 \%$ said that cooking gas was scarce. Other reasons given by respondents for not using cooking gas were: non-uniformity of cylinder regulator when the cylinder is changed at the point of purchase, distance to the points of purchase was far, cooking gas was not sold in small quantities like other energy sources so as to give room for the purchase of smaller quantities like kerosene. 


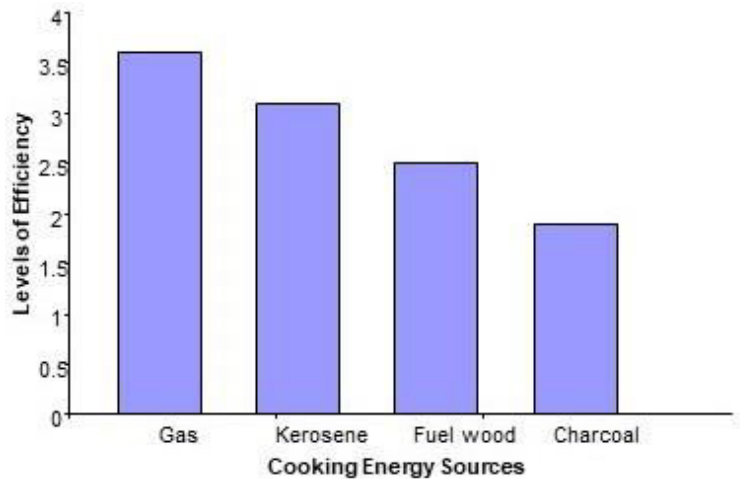

Figure 2: Households perceived levels of efficiency of the energy sources

Table 4: Preference of energy source

\begin{tabular}{|c|c|c|}
\hline Reason & Frequency & Percentage \\
\hline \multicolumn{3}{|l|}{ Preference for LPG } \\
\hline Reduced cases of fire accident & 1 & 0.8 \\
\hline Cooks faster than others & 43 & 31.9 \\
\hline Clean cooking & 42 & 31.0 \\
\hline Can be used for any type of cooking & 14 & 10.4 \\
\hline Easy to use & 24 & 17.8 \\
\hline Gives food a better taste & 10 & 7.4 \\
\hline It is a status symbol & 1 & 0.8 \\
\hline \multicolumn{3}{|l|}{$N=135$} \\
\hline \multicolumn{3}{|l|}{ Preference for kerosene } \\
\hline Reduced cases of accident & 32 & 23.0 \\
\hline Cooks faster than others & 11 & 7.9 \\
\hline Clean cooking & 27 & 19.4 \\
\hline Closeness to source & 18 & 12.9 \\
\hline Can be used for any type of cooking & 14 & 10.1 \\
\hline Easy to use & 25 & 18.1 \\
\hline $\begin{array}{l}\text { Gives food a better taste } \\
N=139\end{array}$ & 12 & 8.6 \\
\hline \multicolumn{3}{|l|}{ Preference for charcoal } \\
\hline Reduced cases of accident & 3 & 21.4 \\
\hline Cooks fast & 1 & 7.1 \\
\hline Clean cooking & 3 & 21.4 \\
\hline Closeness to source & 1 & 7.1 \\
\hline Can be used for any type of cooking & 2 & 14.3 \\
\hline $\begin{array}{l}\text { Easy to use } \\
N=13\end{array}$ & 3 & 21.4 \\
\hline \multicolumn{3}{|l|}{ Preference for fuelwood } \\
\hline Reduced cases of fire accident & 8 & 7.4 \\
\hline Cooks faster than others. & 17 & 15.9 \\
\hline Closeness to source & 8 & 7.4 \\
\hline It is our tradition to use it & 2 & 1.9 \\
\hline Can be used for any type of cooking & 8 & 7.4 \\
\hline Easy to use & 8 & 7.4 \\
\hline Gives food a better taste & 20 & 18.9 \\
\hline Large family size & 19 & 17.8 \\
\hline Lack of kerosene & 17 & 15.9 \\
\hline$N=107$ & & \\
\hline
\end{tabular}

For kerosene, the two major causes of non-use by those that preferred it were high cost and scarcity as both accounted for $37.5 \%$ each, while $25 \%$ do not use it because it is not economical with large family sizes. Thus, as the family size increases, the higher is the tendency to go for cheaper energy sources.

The only reason why some of those who preferred fuelwood for cooking don't use it was that during the rainy season it was always wet and not convenient to get from the forest or when stored outside. Thus, apart from this all the people that prefer it use it as energy source.

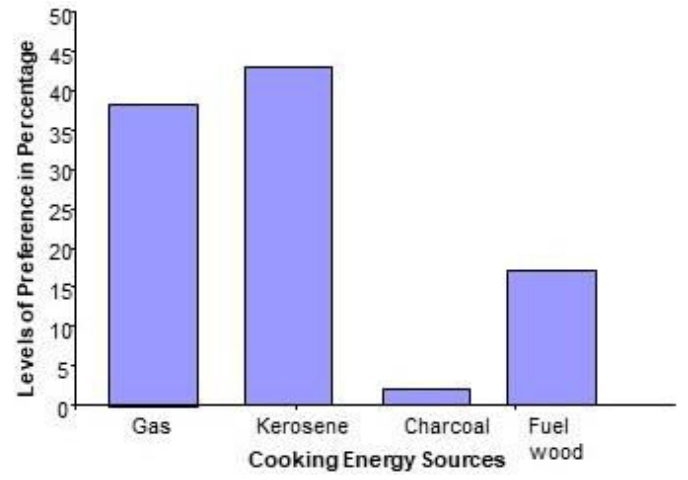

Figure 3: Distribution of households' preferences of different energy sources

\section{CONCLUSION}

The findings of this study show that there is a significant difference between the quantities of kerosene and fuelwood used in the rural and urban areas. The major constraints militating against the use of LPG and kerosene were scarcity and high cost, in addition to risk of fire outbreak as a result of lack of knowledge especially for LPG. In the case of the use of fuelwood and charcoal, the constraints were pollution and production of black soot. The cooking energy with the highest level of efficiency was cooking gas. The two major reasons why households preferred cooking gas were speed of cooking and neatness. The energy with the highest level of preference was kerosene. Thus, though households prefer and understand the need for better and efficient fuel sources in their homes they do not use them primarily due to either because they are scarce or are expensive.

Therefore, this study recommends that government and stakeholders in the energy sector should do more in consumers' education and sensitization on how to use each energy source, especially LPG to limit risk of fire accidents. Also LPG and kerosene should be made more readily available at all times to avoid scarcity. There is also need to implement incentive-based policies to encourage the use of LPG and kerosene, through targeted subsidies and cost reduction for the duo in order to help save our forest and reduce pollution associated with the use of fuelwood and charcoal

\section{REFERENCES}

Bisu D.Y., Kuhe A. and Iortyer H.A. (2016). Urban household cooking energy choice: An example of Bauchi metropolis, Nigeria. Energy, Sustainability \& Society, 6, 15. https://energsustainsoc.biomedcentral.com/ articles/10.1186/s13705-016-0080-1

Baiyegunhi L.J.S. and Hassan M.B. (2014). Rural household fuel energy transition: Evidence from Giwa LGA Kaduna State, Nigeria. Energy Sustainable Development, 20, 30-35

Bonjour S., Adair-Rohani H., Wolf J., et al. (2013). Solid fuel use for household cooking: country and regional estimates for 1980-2010. Environmental Health Perspectives, 121 (7), 784-790 
Chukwu P.U., Ibrahim I.U., Ojosu J.O. and Iortyer H.A. (2014). Sustainable energy future for Nigeria: The role of engineers. Journal of Sustainable Development Studies, 6 (2), 242-259

Daioglou V., van Ruijven B.J. and van Vuuren D.P. (2012). Model projections for household energy use in developing countries. Energy, 37 (1), 601-615

Emagbetere E., Odia J. and Oreko B.U. (2016). Assessment of household eenergy utilized for cooking in Ikeja, Lagos State, Nigeria. Nigerian Journal of Technology, 35 (4), 796-804

ENADEP (2004). Mimie on reorganization of Agricultural Development Programme zones. Enugu State Agricultural Development Programme (ENADEP), $3^{\text {rd }}$ August, 2012

Energy Sector Management Assistance Program (ESMAP) (2007). Strategy to alleviate the pressure of fuel demand on national wood fuel resources, Haiti

Faisal W.A., Brew-Hammond A. and Osei E.E. (2013). Relationships between energy use and income levels for households in Ghana. European Scientific Journal, 9 (6), 233-245

Federal Government of Nigeria (FGN) (2001). First National Biodiversity Report. Abuja: Federal Ministry of Environment and Natural Resources

Hossain K.A. (2012). Global energy consumption pattern and GDP. Int. Journal of Renewable Energy Technol. Resources, 1 (1), 23-29

Karakara A.A., Dasmani I. and Buchenrieder G. (2019). An econometric analysis of domestic fuel consumption in Ghana: Implications for poverty reduction. Cogent Social Sciences, 5 (1). DOI: 10.1080/23311886.2019.1697499

Kumlachew G., Molla G., Zewdu D. and Dube J. (2014). Current level and correlates of traditional cooking energy sources utilization in urban settings in the context of climate change and health, Northwest Ethiopia: A case of Debre Markos Town. BioMed Research International, Article ID 572473, 11. doi.org/10.1155/2014/572473

Lam L.L., Smith K.R., Gauthier A. and Bates M.N. (2012). Kerosene: a review of household uses and their hazards in low- and middle-income countries. J. Toxicol. Environ. Health B. Crit. Rev., 15 (6), 396-432. Doi: 10.1080/10937404.2012.710134. Retrieved from https://www.ncbi.nlm.nih.gov/pmc/articles/PMC3664014/

Malla S. and Timilsina G.R. (2014). Household cooking fuel choice and adoption of improved cookstoves in developing countries: A review. Policy Research Working Paper 6903. The World Bank Development Research Group; Environment and Energy Team.http://econ.worldbank.org
Massawe F.A., Bengesi K.M.K. and Kweka A.E. (2015). Patterns of household cooking energy and associated factors: Experience from Kilimanjaro Region, Tanzania. Intersect: The Stanford Journal of Science, Technology and Society. 8 (3), 1-25

Mwampamba T.H., Ghilardi A., Sander K. and Chaix K.J. (2013). Dispelling common misconceptions to improve attitudes and policy outlook on charcoal in developing countries. Energy Sustain. Dev. 17, 75-85

National Bureau of Statistics (NBS) (2018). 2017 Demographic Statistics Bulletin, pp. 1-26

Nnaji C.E., Ukwueze E.R. and Chukwu J.O. (2012). Determinants of household energy choices for cooking in rural areas: Evidence from Enugu State, Nigeria. Continental Journal of Social Sciences, 5 (2), 1-11

Ogwumike F.O., Ozughalu U.M. and Abiona G.A. (2014). Household energy use and determinants: Evidence from Nigeria. International Journal of Energy, Economic Policy, 4 (2), 248-262

Olufemi O., Desalu O., Ololade O., Ebenezer K., Tolutope F. and Ayodele I. (2012). A community survey of the pattern and determinants of household sources of energy for cooking in rural and urban Southwest, Nigeria. The Pan African Medical Journal, 12 (2). doi:10.11604/pamj.2012.12.2.1436

Otte P.P. (2014). Warming up to solar cooking- a comparative study on motivations and the adoption of institutional solar cookers in developing countries. Energy Procedia, 57 (1876), 1632-1641. doi.org/10.1016/j.egypro.2014.10.154

Oyedepo S.O. (2012). Energy and sustainable development in Nigeria: The way forward. Energy, Sustainability and. Society, 2, (15), 1-17

Risseeuw N. (2012). Household Energy in Mozambique: A Study on the Socio-economic and Cultural Determinants of Stove and Fuel Transitions. Research Project, IVM Institute for Environmental Studies. http://www.ivm.vu.nl/en/Images/Risseeuw_NatashaFINAL THESIS tcm234-352225.pdf

Tchereni B.H.M. (2013). An economic investigation into fuelwood demand behaviour in South Lunzu township in Malawi. Developing Countries Studies, 3 (4), 153-159

World Health Organization (WHO) and United Nations Development Programme (UNDP) (2009). The energy access situation in developing countries: A review focusing on the least developed countries and Sub-Saharan Africa. New York

Yonemitsu A., Njenga M., Iiyama M. and Matsushita S. (2015). A choice experiment study on fuel preference of Kibera slum households in Kenya. Int. Journal of Environmental Science Development, 6 (3), 196-200 